\title{
ГУМАНИТАРИЗАЦИЯ ЕСТЕСТВЕННОНАУЧНОГО МЫШЛЕНИЯ: ОТ XVII СТОЛЕТИЯ ДО НАШИХ ДНЕЙ
}

\begin{abstract}
В.Т. Ополев
Гуманитаризация научно-технической деятельности и связанного с нею образования - процесс, который достаточно интенсивно формировался в течение последних, примерно, четырех десятилетий, хотя отдельные его предпосылки начали складываться значительно раньше. $\mathrm{B}$ настоящее время этот процесс достиг того уровня развития, когда в нём проявились две существенные черты. Во-первых, с гуманитаризацией стали связывать надежду на решение ряда социальных и методологических проблем научно-технического прогресса. Среди первых центральное место занимает проблема гуманизации научно-технической деятельности, под которой понимают прежде всего преодоление наметившегося расхождения в тенденциях развития общества, с одной стороны, и сферы науки и техники - с другой, создание средств эффективного контроля и управления последними и в конечном итоге превращение их в органическую и в то же время подчинённую часть общественных процессов. Методологические проблемы связаны с совершенствованием оснований научного и инженерного мышления, созданием субъективных предпосылок для получения качественно новых результатов. Наука и техника должны служить человеку, но для этого они сами должны быть максимально очеловечены. Во-вторых, в общественном сознании стали формироваться особые идейные образования, посредством которых стихийно складывающаяся тенденция гуманитаризации начала превращаться в целенаправленно организуемый процесс. Эти идейные образования независимо от степени их
\end{abstract}

Актуальні проблеми духовності

(Відп. ред.: Я.В. Шрамко)

Кривий Ріг (2007), 225-235 
разработанности и других характеристик представляют собой некоторого рода программы [9], поскольку их основная функция, в конечном итоге, - организация деятельности.

Таково на сегодняшний день общее понимание проблемы, исследование которой составляет цель настоящей статьи, а задачи её заключаются в раскрытии условий и своеобразных «механизмов», сложившихся в европейской культуре ещё в период научной революции XVII века и обусловивших вполне определённый характер взаимоотношений между естественными и гуманитарными науками и соответствующими им способами мышления.

Превращение объективной тенденции в сознательно организуемый процесс требует, в первую очередь, уяснения себе существа этой тенденции, выработку такого её понимания, которое отвечало бы, по крайней мере, двум следующим требованиям. Если этого не будет, то сознательные усилия рискуют быть неэффективными. Прежде всего, соответствующее понятие и обрамляющие его представления должны быть достаточно чёткими и ясными, чтобы допускать конкретизирующие интерпретации. Популярная среди учёных нового времени максима гласит: ясные понятия, даже если они неправильные, могут приводить к интересным результатам, тогда как путаница в понятиях всегда бесплодна. Назовём это требованием конструктивности. Второе требование относится к содержанию понятия. Оно должно быть настолько общим, чтобы могло охватить весь комплекс взаимосвязанных в рамках исследуемого процесса проблем, и в то же время семантика его должна максимально соответствовать условиям той социо-культурной ситуации со всеми её субъективными и объективными предпосылками, которые инициировали и питают жизненность рассматриваемого процесса. Конечно, в реальности к выполнению всех этих требований можно лишь в той или иной степени приблизиться, но и это создаёт необходимые предпосылки для разработки программ, организующих продуктивную деятельность. Выполнение такой работы относится к задачам философско-методологического анализа, отдельным аспектам которого и посвящена данная статья.

На сегодняшний день в рамках процесса гуманитаризации научнотехнической деятельности можно констатировать существование двух основных программных ориентаций. Первая из них фигурирует под названием проблемы взаимодействия общественных, естественных и технических наук [4]. Вторая - это собственно программа «гуманитаризации», которая сейчас заметно прогрессирует. В подтверждение последнего достаточно указать на процессы, происходящие в связи с 
перестройкой высшего технического и естественнонаучного образования. По существу, каждая из программ представляет собой модификацию одной идеи. Эту идею предельно коротко можно было бы выразить так: признание того, что многие проблемы, возможность решения которых связывалась исключительно с естественнонаучным и техническим мышлением, содержат существенные гуманитарные аспекты, что делает их неразрешимыми без применения гуманитарных знаний и соответствуюшей культуры мышления. Признается также, что последняя принципиально несводима к естественнонаучному мышлению и поэтому не может быть заменена им даже в отдаленной перспективе.

Программы различаются между собой элементами трактовки указанной идеи. Например, вторая программа охватывает большее число вопросов, о которых идёт речь, в частности, сюда включаются такие проблемы, которые, в общем-то, относятся к прерогативе гуманитарных наук, но относительно которых в обществе сложилась практика и даже закрепляющая её идеология решать их на основе стандартов естественнонаучной и технической рациональности. Вторая программа отличается ещё одним положением, которое, на наш взгляд, настолько существенно, что его необходимо рассмотреть специально. Этот анализ даёт возможность оказаться как бы в самом центре ситуации, характерной для современного состояния процесса гуманитаризации научно-технической деятельности.

В рамках первой программы предполагается известное методологическое равноправие трёх комплексов наук, при котором каждому из них находится своё функциональное место при решении каких-то, главным образом прикладных, проблем. В рамках второй-значение гуманитарных дисциплин значительно усиливается, и они получают некоторый особый, выделенный статус. Естественно, это касается не всех аспектов взаимоотношений наук, однако в некоторых из них подобная тенденция имеет место. Приведём в этой связи определение, взятое нами из предисловия к сборнику статей, посвящённому методологии гуманитарных наук, гуманитаризации и гуманизации науки: «под гуманитаризацией естествознания обычно понимают проникновение ценностей, стандартов гуманитарного познания в структуру естественнонаучной деятельности, т. е. изменение внутренних ориентиров науки» $[8$, с. 5]. Выраженное в данном определении понимание рассматриваемого предмета допускает в качестве методологической основы и вполне логически совместимо с некоторым фундаментальным представлением, укоренившемся в современном методологическом самосознании науки (см.: [5]). 
Суть этого представления можно описать следующим образом. Имеющиеся научные достижения делятся на две основные категории. В первую определяются те из них, которые в настоящий момент считаются наиболее совершенными и развитыми областями исследований. Эти результаты - научные дисциплины, фундаментальные теории, отдельные разделы науки и т. д. - воплощают в себе идеал научности, на языке современной методологии их называют лидерами [11, с. 22-23]. Во вторую категорию попадают все остальные научные достижения, самостоятельная ценность которых признаётся, главным образом, в области того или иного узкого направления исследований, в методологическом же плане им предписывается следовать за лидирующими областями знаний.

Как нетрудно заметить, такое разделение научных областей и утверждение определённых взаимоотношений между ними представляет собой вместе с тем описание некоторого механизма развития научного знания или, точнее сказать, научной деятельности и связанного с нею мышления. Развитие происходит за счет того, что нормы рациональности, сформировавшиеся в одной области науки, начинают транслироваться в остальные и благодаря этому происходит сдвиг в развитии науки в целом [6]. Можно, в принципе, построить реконструкцию становления научного мышления, основываясь на представлении об этом механизме. В современной историко-научной, методологической и даже научно-популярной литературе можно встретить фрагменты подобной реконструкции.

Этот механизм, по-видимому, достаточно универсален, и его действие можно обнаружить в различных областях культуры. Особое значение в науке и, можно сказать, довольно жёсткий характер он стал приобретать вместе с процессом стремительного развития естествознания, начавшегося в XVII веке. Одно из последствий этого развития состояло в том, что некоторые разделы естествознания и вместе с ними математика, которая и до этого имела достаточно высокий методологический статус в духовной культуре, прочно закрепились на роли лидеров в науке. И этот механизм развития через лидерство первоначально формировался, будучи неразрывно слит с определённой его конкретной интерпретацией, что и сейчас в какой-то мере является одним из препятствий на пути его осознания как чего-то самостоятельного. Лидирующее положение указанных разделов науки находило выражение и закреплялось философскими учениями: в XVII-XVIII столетиях - механицизмом, в XIX-XX - позитивизмом. В полной мере последнее можно отнести и к работам философов-марксистов. В 
качестве лидеров науки рассматривались в разное время математика, физика, кибернетика, биология. В этих условиях стандарты естественнонаучного мышления оказывали сильное влияние на гуманитарное познание, практически навязываясь ему.

Экспансия естественнонаучной рациональности, к которой со временем добавилась техническая, при благоприятствовавших тому социальных условиях породила так называемый технократизм. Несмотря на известную неоднозначность, характерную для употребления термина «технократизм», можно указать существенный признак, позволяющий распознать соответствующее явление. Технократизм - это применение определённого, сформировавшегося в сфере естественнонаучной и технической деятельности способа мышления для решения проблем, относящихся к другим областям культуры. Технократизм, таким образом, - это некоторое состояние общественной практики, характеризующееся тем, что её доминирующей формообразующей основой оказывается естественнонаучная рациональность.

Идеология технократизма основывается на убеждении, что таким путём можно решить любые проблемы, а если же какие-то из них в настоящее время, несмотря на все усилия, не получают удовлетворительного решения, то это свидетельство того, что соответствующий способ мышления ещё недостаточно развит и дело лишь в его дальнейшем совершенствовании. В свою очередь, антитехнократизм основывается на утверждении о принципиальной ограниченности возможностей естественнонаучных и технических подходов к решению проблем. Общее состояние общественной практики, пронизанной технократизмом, можно было бы сравнивать с воображаемым положением дел, например, в медицине, если бы в ней господствовало убеждение, что все заболевания можно по-настоящему вылечить только хирургическим путём и все остальные способы лечения при этом либо отвергались, либо рассматривались как временные, вынужденные, неадекватные замены работе скальпеля.

Однако естественнонаучная рациональность-методологическая основа технократизма - имеет в своём составе норму, ограничивающую её претензии на всеобщую и безусловную значимость. Естественнонаучное и основывающееся на его результатах инженерное мышление всегда понимаются как направленные вовне, на природный, чувственно воспринимаемый объект, отличный и пространственно отделённый от самого мыслящего субъекта. С этим связана и существенная онтологическая характеристика указанного объекта: его абсолютная независимость и устойчивость относительно содержания тех знаний о 
нём, которыми располагает познающий субъект. Знания могут быть истинными или ложными, доказанными или предположительными, достаточно полными или фрагментарными, они могут быть фиксированы в различных формах, однако, согласно установкам естественнонаучного мышления, всё это никак не может повлиять на природу исследуемого объекта. Но существуют такие области, или, точнее сказать, ситуации познания, которым указанные установки неадекватны. $\mathrm{K}$ ним, в частности, принадлежит сфера нравственной и методологической рефлексии субъекта познания. Природа так называемых систем с рефлексией, к которым наряду с другими отраслями творчества относится и наука как специфический вид мышления и деятельности, такова, что от содержания и организации её рефлексивного компонента существенно зависят свойства системы в целом [10, с. 100-124].

Вместе с тем одна из особенностей мышления современной науки заключается в том, что в ней неизменно возрастает функциональная нагруженность так называемой «стихийной» рефлексии, т. е. того «мышления о мышлении», которое не будучи выделенным в особую деятельность осуществляется самими учёными в процессе научного поиска, профессионального информационного обмена и преподавания. Ситуативно меняющееся содержание рефлексии - один из факторов, определяющих результаты этих видов деятельности. Учёные-естественники и инженеры оказываются вынужденными в той или иной форме осуществлять подобную рефлексию и использовать её результаты. Совершающийся при этом как бы «само собой разумеющийся» перенос стандартов естественнонаучной и технической рациональности в сферу методологического и нравственного самосознания порождает явление, которое можно назвать «внутренним» технократизмом [7]. Его отличительные черты: во-первых, видеть в мышлении как объекте познания только те сущности и связи, которые соответствуют форме фундаментальных схем естественнонаучных теорий. Эвристические рассуждения здесь строятся, как правило, просто по аналогии. Во-вторых, требовать от результатов рефлексии того же набора «совершенств», которыми обладают естественнонаучные знания: строгости, теоретичности, системности, формализуемости, технологичности и т. д. Всё это, с одной стороны, приводит к упрощённым представлениям о собственном мышлении, характерном для многих технических специалистов, с другой - в виду невыполнимости некоторых установок порождает у них нежелание интересоваться соответствующими проблемами.

В связи со сказанным становится очевидной одна из «пружин», 
приводящих в движение процесс гуманитаризации науки, - это стремление гуманитарного познания к методологической эмансипации. Начало соответствующей борьбы можно, пожалуй, отнести ко второй половине XIX века, когда в философии неокантианцев Баденской школы и работах В. Дильтея стала разрабатываться идея методологического разделения «наук о духе» и «наук о природе» [2, с. 108-135]. Гуманитаризацию науки в наше время можно рассматривать, в частности, и как следующий этап борьбы гуманитарного знания за методологическую самостоятельность. Он характеризуется тем, что обе стороны в достаточной степени осознают многообразие серьёзных взаимообусловленностей, существующих между ними. С одной стороны, ни точные науки, ни науки о человеке, как оказалось, не могут развиваться обособленно, подобно «двум культурам» (известное выражение Ч.П. Сноу), с другой - имеется множество практических проблем, решение которых требует их взаимодействия. Таким образом, и духовный, и практический контакт этих сфер познания неизбежен.

Когда стихийно складывающийся процесс в сфере человеческой практики переходит в фазу сознательно организуемого, далеко не безразлично для его результатов, какие методологические основания будут определять построение соответствующих программ. Теперь мы снова должны вернуться к обсуждению того методологического представления («развитие через лидерство»), о котором речь шла выше. Если оно будет воспринято программой гуманитиризации в том виде, в каком оно наиболее часто употребляется сегодня, то соответствующий процесс приобретёт ряд особенностей, которые вполне можно предвидеть.

Лидеры точных наук теряют свой безусловный общенаучный методологический авторитет. Вот, например, как это явление применительно к математике описывает М. Клайн: «Кризис математики и порождённые им конфликты по поводу того, что такое настоящая математика, отрицательно сказались и на применении математической методологии ко многим областям культуры: к философии, социальным и политическим наукам, этике и эстетике. Надежда на то, что удастся найти объективные, непреходящие законы и эталонные образцы знания, развеялись. „Век разума“ закончился» [3, с. 16]. Естественно, что, следуя логике, определяемой рассматриваемым методологическим основанием, на это место будут выдвигаться гуманитарные науки.

Этому выдвижению могут способствовать также и некоторые социально-психологические факторы. Клайн в той же работе характеризу- 
ет как трагические ощущения математиков, связанные с потерей этой дисциплиной методологического лидерства, и это несмотря на то, что в других аспектах она развивается вполне благополучно. Приобретение же подобного лидерства, как можно ожидать, будет сопровождаться воодушевлением, способным обладать ценностью само по себе.

Действие указанных причин может направить процесс развития науки таким образом, что гуманитарное познание займёт в нём то место, которое прежде принадлежало естествознанию и математике. История, следовательно, повторится, хотя и с обратным знаком, но с похожими издержками. На смену технократизму придёт некий «гуманитаризм» - другая крайность в развитии науки и культуры, которая, как известно, уже имела место в истории, например, в средневековой Европе.

Как мы видим, отношения в плане методологии между естественнонаучным и техническим мышлением, с одной стороны, и гуманитарным, с другой, имеют тенденцию приобретать форму своеобразного господства и подчинения. Последнее возникает тогда, когда соответствующий «лидер» уже определился, и положение его достаточно прочно. Если этого нет, то, как правило, происходит в тех или иных видах борьба за лидерство, взаимоотношения получают форму соперничества, вступают в конфликтную фазу. И, наконец, в тех случаях, когда какая-то из сторон «устаёт» от такого рода взаимодействия, она стремится замкнуться в себе и существовать обособленно. Все эти формы отношений между «двумя культурами», чередуясь друг с другом, достаточно устойчиво воспроизводятся в культуре.

Вместе с тем необходимо признать, что, каково бы ни было по характеру указанное взаимодействие, оно всё же приводит к некоторым положительным сдвигам в развитии методологических основ каждой из сторон. Однако, это развитие в подобных условиях, во-первых, всегда связано с немалыми трудностями и потерями, во-вторых, оно происходит очень медленно. Линия развития здесь имеет зигзагообразные очертания: технократизм сменяется «гуманитаризмом»и наоборот. Было бы, естественно, лучше, если бы эту линию удалось каким-то образом выпрямить.

Для этого должен кардинально измениться характер рассматриваемых взаимоотношений, им необходимо приобрести форму того, что можно было бы назвать понимающим взаимодействием [1], а от развития, основанного на лидерстве, придется отказаться. Таким образом, мы можем сказать, что в рамках современной программы гуманитаризации необходимо решать одновременно две проблемы. Первая из 
них связана с тем, о чём мы уже говорили выше, а именно: усиление влияния естественных и технических наук в определённых областях современной культуры достигло того предела, когда оно становится уже более вредным, чем полезным. В дополнение к этому становится всё более ощутимым, что с точки зрения присущих указанным наукам методологических основ или, как ещё принято говорить, форм и стандартов рациональности их развитие зашло в некоторого рода тупик, и требуется внешнее воздействие для того, чтобы из него выйти. На этой почве и возникает интерес к методологии гуманитарных исследований.

Вторая проблема касается поиска и практического внедрения таких принципов взаимоотношений между рассматриваемыми областями культуры, которые бы создавали более оптимальные условия для развития как каждой из них, так и культуры в целом. Первую из этих проблем мы уже в основных чертах охарактеризовали в рамках того, что было изложено выше, теперь мы рассмотрим вторую.

Знакомство с методологией гуманитарных наук для учёных-естественников и инженеров необходимо вовсе не для того, чтобы переносить в сферу решения своих специальных проблем стандарты гуманитарного мышления, а в первую очередь для того, чтобы было с чем сравнивать и сопоставлять присущий им самим образ мышления. В результате такого сопоставления должно происходить углубление понимания ими основ собственной интеллектуальной деятельности, расширение и уточнение знаний о них, а это, в свою очередь, не может не способствовать развитию последних. Конечно же, в рамках этого процесса могут происходить и переносы определённых методологических установок из одной области в другую. Однако этот перенос не должен быть главной задачей рассматриваемого взаимодействия, он не может также происходить в виде копирования, буквального воспроизведения стандартов рациональности, присущих одной сфере, в рамках другой и осуществляться чуть ли не путём насильственного внедрения (всё это было весьма характерным для процесса сциентизации гуманитарных наук), а быть обоснованным и взвешенным.

Кроме того, в связи с тем, что в современных условиях творчество, имеющее отношение к решению специальных проблем, приобретает всё более коллективный характер, причём в такие коллективы нередко объединяются учёные самых разных специальностей, возникает еще, по крайней мере, две серьёзные проблемы, непосредственно связанные с гуманитарной методологией. Во-первых, деловое общение, обмен релевантной информацией между, скажем, инженером и специалистомгуманитарием требует от каждого из них адекватного понимания обра- 
за мышления своего оппонента и методологических особенностей соответствующих знаний. Во-вторых, само межсубъектное взаимодействие, независимо от того, кем по специальности являются его участники, относится к гуманитарным проблемам. Здесь существует своя, достаточно сложная деятельность, связанная с приёмом и передачей знаний, и от того, насколько она будет правильно организована, зависит эффективность совместных усилий. В связи с этим требуется уже не просто знакомство с методологией гуманитарных наук, но и определённое владение ею. Однако, хотелось бы ещё раз подчеркнуть, что речь в последнем случае не идёт о том, чтобы стандарты рациональности гуманитарного мышления распространялись на деятельность, непосредственно связанную с решением собственно технических или естественнонаучных задач, напротив, они должны применяться только в сфере информационного взаимодействия.

Вместе с тем, информационное взаимодействие - это только одна область гуманитарных проблем, возникающих в рамках естественнонаучной или технической деятельности. Другая, не менее значительная, - методологическая рефлексия или методологическое самосознание. Последнее является неотъемлемым компонентом любого специализированного мышления, в значительной мере определяющим его продуктивность [7].

В современных условиях обе эти сферы гуманитарных по своей природе проблем находятся под сильным воздействием стандартов естественнонаучного и технического мышления. Это явление можно назвать внутренним сциентизмом. Процесс гуманитаризации должен быть направлен на преодоление этого вида сциентизма и создание предпосылок для интенсивного развития соответствующих аспектов научно-технической деятельности. K этому стоит добавить также, что многое из того, что было сказано по поводу внутренних аспектов технической деятельности, может быть вполне отнесено и к сфере соответствующего профессионального образования. Там имеют место совершенно аналогичные проблемы, решение которых связано с процессом гуманитаризации.

В заключение вернёмся ещё раз к выводам, уже в какой-то мере прозвучавшим в данном исследовании. Целый ряд предпосылок и «механизмов», обусловливавших развитие науки на протяжении достаточно длительного времени и, безусловно, сыгравших положительную роль в этом процессе, приводит к тому, что, в одних случаях, можно назвать глобальной гуманитаризацией, в других - глобальной сциентизацией научного мышления в целом. Поэтому действие указанных 
предпосылок и социальных «механизмов» необходимо «смягчить», а это можно сделать только путём определённого развития методологического самосознания ([5], [7]) соответствующих видов специализированного мышления.

\section{1 Литература}

[1] Гадамер Х.-Г. Истина и метод: Основы философской герменевтики. - М.: Прогресс, 1988.

[2] Дильтей В. Введение в науки о духе // Заруб. эстетика и теория литературы 19-20 вв. - М.: Изд-во МГУ, 1987. - С. 108-135.

[3] Клайн М. Математика. Утрата определенности. - М.: Мир, 1984.

[4] Методологические проблемы взаимодействия общественных, естественных и технических наук. - М.: Наука, 1981.

[5] Методологическое сознание в современной науке. - Киев: Наукова думка, 1989.

[6] Ополев B.T. Специализированное мышление: рациональность, рефлексия, творчество // Образование и культура. Ежегодник. 1994год. - Новосибирск, 1994. - С. 38-54.

[7] Ополев В.T. Специфика языка методологической рефлексии // Философия рефлексивного мышления.-Новосибирск, 1992.C. 129-149.

[8] Проблемы гуманитарного познания. - Новосибирск: Наука, 1986.

[9] Розов М.А. Понятие исследовательской программы // Исследовательские программы в современной науке. - Новосибирск: Наука, 1987.- C. 7-26.

[10] Розов M.А. Проблемы эмпирического анализа научных знаний. Новосибирск: Наука, 1977.

[11] Степин B.C. Идеалы и нормы в динамике научного поиска // Идеалы и нормы научного исследования. - Минск: Изд-во БГУ, 1981. - C. 10-64. 